\title{
Foreign Exchange Reserves Demand Model Based on Chinese Government Utility Maximization and Analysis of Chinese Foreign Exchange Reserves*
}

\author{
Shihong Zeng \\ School of Economics \& Management, Beijing University of Technology, Beijing, China \\ E-mail: zengshihong2000@yahoo.com.cn \\ Received April 15, 2011; revised April 25, 2011; accepted June 3, 2011
}

\begin{abstract}
At the end of 2010 China's foreign exchange reserve reached $\$ 2847.34$ billion, the author designs the maximum government utility function when consider the China government buys a part foreign exchange if company earns, it means that the China government will increase Ren-Min-Bi Yuan. And it will cause inflation. The inflation will cause disutility to government. Finally it gets the optimal fuction. VAR Regress finds the fitted value and actual value of foreign exchange reserves is nearly equal within $99.8 \%$. The thesis gets the long term equilibrium relation of the nature logarithm of variables by VEC model, which are foreign exchange reserves, standard error of export, marginal propensity to import, the opportunity cost for foreign exchange reserves, marginal output to export. Using the sample datas in China 1980-2006 and VEC, we can find that 1) the government-holding foreign exchange reserves has positive correlation with the export standard error, 2) the government-holding foreign exchange reserves has positive correlation with the marginal propensity to import. The data and regression method are all different, but all have the positive correlation between the foreign exchange reserves and export standard error.
\end{abstract}

Keywords: Foreign Exchange Reserves, Demand Model, Chinese Government, Utility Maximization

\section{Introduction}

This template, In order to study demand model of optimal foreign exchange reserves based on Chinese government utility maximization and analysis of Chinese foreign exchange reserves, the thesis arranges as the followings: the first section designed the demand model of optimal foreign exchange reserves based on Chinese government utility maximization, the second section analyzed the unit root test and cointegration of optimal foreign exchange reserves based on government utility maximization, the third section analyze VAR and VEC model of optimal foreign exchange reserves based on government utility maximization, the fourth section is the summary of this thesis.

\footnotetext{
*This work was achievements of the current stage of 2010 Statistical Science key research program of China (No. 2010LB33) and 2010 talent to deepen teaching plan in Beijing University of Technology
} (01100054R6002).

\section{Demand Model of Optimal Foreign Exchange Reserves Based on Chinese Government Utility Maximization}

In order to study the demand model of optimal foreign exchange reserves based on Chinese government utility maximization, the thesis arrange as the followings: First, the authors analyzes the significance and objectives of the research, then review the literature simply. Based on Kelly, Michael G. (1970), consider the China government buy part foreign exchange as oreign exchange reserves if company earn oreign exchange, it means that the China government will increase supply of Ren-MinBi Yuan, and it will cause inflation. The inflation will cause disutility to government that is a negative government utility, combining with the outputting fluctuation, the foreign exchange reserves make the resource to be unused and lead to a negative social welfare, then design the following government utility function. Finally get the 
demand model of optimal foreign exchange reserves based on government utility maximization.

\subsection{Significance and Objectives of the Research}

\subsubsection{Research Significance}

December 31, 2003, the Chinese government completed the capital injection of $\$ 45$ billion foreign exchange reserve into Bank of China and Bank of Construction. This capital injection played a substantial role in stabilizing and strengthening China's domestic banks. At the end of 2010 China's foreign exchange reserve reached $\$ 2847.34$ billion, which had played an important role in supporting Chinese REN MIN BI YUAN (RMB) appreciation. In an open economy, a foreign exchange reserve is an important index to study a country's international economic relations; it reflects results of the macroeconomic operation and functions as an important means of macroeconomic control. The foreign exchange reserve in fact affects many aspects of macro economy: it helps to understand a country's macroeconomic operation; the adjustment of the reserve level can achieve domestic and international economic balances and realize the established macroeconomic objectives. A country's foreign exchange reserve should fit its actual economic development. A sufficient foreign exchange reserve can ensure a country's international payment capability, its ability to intervene in the foreign exchange market, as well as its international credibility. At the same time, an excessive foreign exchange reserve can lead to the waste of its resources. This is because owning a sizable foreign exchange reserve by a country means providing foreign countries with some of its own resources while giving up opportunities to use foreign recourses to increase its domestic investment and economic development. It is true that a limited foreign exchange reserve will negatively affect domestic economic development, the government's capabilities to intervene in the foreign exchange market and to balance international revenue and expenditure. All this can weaken a country's capability to meet international capital shock and to avoid financial crisis, which will not help, in our case, China's financial enterprises/companies to 'get into the world.' Therefore, the study of the optimal scale of a country's foreign exchange reserve is crucial to the country's credibility, stability as well as to understanding the international financial environment into which Chinese financial enterprises/companies are entering.

\subsubsection{Research Objectives}

The thesis finishes the following researches, the author designs the maximum government utility function when consider the China government buys part foreign ex- change if company earns, it means that the China government will increase Ren-Min-Bi Yuan, and it will cause inflation. The inflation will cause disutility to government. Then it gets the optimal foreign exchange reserves. Finally unit root test, cointegration test, vector autoregressive model analysis, vector error correction model analysis and the long term equilibrium relation of the variables which the optimal foreign exchange reserves function include.

\subsection{Literature Review}

The Heinz Robert Heller (1966) constructed the demand of reserves. Heller's model is the beginning of cost revenue. After that time, many scholars have developed Heller's pattern and obtained their results. He pointed out that holding the reserves exist opportunity cost. The expression is the loss of investment benefit owing to holding reserves. When marginal cost equals to marginal proceeds, international reserve achieved the proper scope [1].

Clark (1970) has extended Heller's method and developed a random pattern, considered the opportunity cost for holding foreign exchange reserves, then constructed the government utility function. He reached: 1) the random error item of standard error has positive correlated between foreign exchange reserves and optimal foreign exchange reserves; 2) It has negative correlated between optimal foreign exchange reserves and marginal propensity to import; 3 ) The opportunity cost for holding foreign exchange reserves more, the optimal foreign exchange reserves less [2].

Kelly. Michael G. (1970) thought that holding foreign exchange reserves has an opportunity cost. According to this, he constructed the utility function. At last, he achieved the optimal foreign exchange reserves function be means of the utility function. He found that there has positive correlated between the foreign exchange reserves holding by government and the standard error of export, in the same time has positive correlated with the average propensity to import [3].

Guobo Huang (1995) has collected the economic data about China during 1980 to 1990 . He researched the international reserve scale of China by using of ECM and discovered that: 1) The Chinese foreign exchange reserve has the negative correlation with import, that is when the import increased the foreign exchange reserves will reduce; 2) It has negative correlation with average propensity to import, that is when the average propensity to import increased the foreign exchange reserves will reduce; 3) The Chinese government has an ability to adjust the foreign exchange reserves, but the ability will reduce without considering the net foreign exchange reserves of China Bank [4]. 
Yu Yongding (1997) found Chinese foreign exchange reserves are higher than reasonable and optimal foreign exchange reserves [5].

$\mathrm{Wu}$ (1998) combined the ratio analysis method and the factor analysis method to study the determinant of reasonable Chinese foreign exchange reserves. He assumed that the Chinese demand foreign exchange reserve consists of four aspects: foreign exchange demanded for imports, foreign exchange demanded for repaying the total foreign debt balance, exchange demanded for profits return from foreign direct investment and foreign exchange reserves demand for the country's intervention in the foreign exchange currency market. He also established a linear equation model. The purpose of his thesis was to determine reasonable foreign exchange reserves for China, so he did not determine the equation's parameters with time-serial data or test the equation [6].

According to $\mathrm{Xu}$ (2001), the amount of currency in circulation imposes a more notable impact on the foreign exchange reserve in the short-term than does money and quasi-money. In addition, he also found that a long-term equilibrium relationship between the average propensity to import and the demand for foreign exchange reserves does not exist, yet the variation of a short-term average propensity to import exerts comparatively notable negative impacts on foreign exchange reserves. The reason is that under the current foreign exchange supervision system, an increase in imports means that a country would have to sell more foreign exchange, which would result in a decrease in the volume of foreign exchange reserves that are held [7].

Victoria miller (2006) support China to use foreign exchange reserves to save Chinese banks and Asian bank [8]. M. Ramachandran (2006) finds the asymmetric control over capital flows and asymmetric intervention in favour of strengthening export competitiveness in an era of persistent capital inflows seem to be responsible for large stockpile of reserves in India [9].

Adnan Kasman and Duygu Ayhan (2008) find that exchange rate Granger causes foreign exchange reserves in the long-run nominal [10].

Victor Pontines and Ramkishen S. Rajan (2011) find that Asian central banks react more strongly to currency appreciations than depreciations and more to nominal effective exchange rates (NEERs) than to bilateral US dollar rates. This rationalizes the relative exchange rate stability and the sustained reserve accumulation in the region [11].

\subsection{Design of Government Utility Function}

\subsubsection{Kelly, Michael G. (1970) Design of Government Utility Function}

Kelly, Michael G. (1970) designed the government util- ity function without considering the China government buys part foreign exchange if company earn, it means that the China government will increase Ren-Min-Bi Yuan, and it will cause inflation. The inflation will cause disutility to government.

Because the change of foreign exchange reserves equal to export increment subtract import increment, so

$$
\Delta R t=\Delta X t-\Delta M t
$$

where $R$ is the foreign exchange reserves, $X$ is the export, $M$ is the import.

Suppose that the reaction coefficient of import to export is $f=\mathrm{d} M / \mathrm{d} X$. Suppose that the reaction coefficient of income to export is $g=\mathrm{d} Y / \mathrm{d} X$, where $Y$ is income

Because the marginal propensity to import is

$$
m=\mathrm{d} M / \mathrm{d} Y
$$

So $f=\mathrm{d} M / \mathrm{d} X=m g=(\mathrm{d} M / \mathrm{d} Y)(\mathrm{d} Y / \mathrm{d} X)$

From Equation (1) we have

$$
\begin{gathered}
\Delta R=\Delta X(1-f) \\
V(R)=E\left(\Delta R^{2}\right)=V(X)(1-f)^{2}
\end{gathered}
$$

$V$ is the variance in Equation (3); Equation (3) suggests that: the variance of foreign exchange reserves equal to the expectation of the squared of change amount of foreign exchange reserves

Use the same arguments that:

$$
V(Y)=E\left(\Delta Y^{2}\right)=g^{2} V(X)
$$

$g=\mathrm{d} Y / \mathrm{d} X$ in Equation (4), where $Y$ is income

The government won't hope to run out the foreign exchange reserves, or we can say that the government hope keep lowest foreign exchange reserves $R^{1}$, so its target is to keep enough foreign exchange reserves as more as they can, to make it almost impossible that the foreign exchange reserves they kept lower than their target amount $R^{1}$, and satisfied the following Equation,

$$
P\left[R<R^{1} \mid E(R), V(R)\right]=e
$$

$e$ in Equation (5) is a very minor number, for any arbitrarily given and ruled probability density function, arbitrarily given e, educes $\mathrm{d} E(R) / \mathrm{d} V(R)>0$, which suggests that if the variance of foreign exchange reserves is greater, in order to keep a arbitrarily given probability e of the ruled foreign exchange reserves $R^{1}$, the average of foreign exchange reserves required is greater.

Suppose that probability e is positive with $\mathrm{V}(\mathrm{R})$, and is negative with $E(R)^{2}$, gives:

$$
e=c V(R) / E(R)^{2}>0
$$

Equation (6) has characteristic that $\partial e / \partial E(R)<0$, $\partial^{2} e / \partial E(R)^{2}>0, \partial e / \partial V(R)>0$, and for the arbitrarily 
given $e, \mathrm{~d} E(R) / \mathrm{d} V(R)>0$, from Equation (3) and Equation (6) we can get the average level of foreign exchange reserve is that,

$$
E(R)=(c / e)^{1 / 2} S(R)=(c / e)^{1 / 2} S(X)(1-f)
$$

where $S(X)$ is the standard error of the export $X$

From Equation (4) we can get $g=S(Y) / S(X)$, put $f=m g$ and $g=S(Y) / S(X)$ into Equation (7),

$$
E(R)=(c / e)^{1 / 2}[S(X)-m S(Y)]
$$

Because keeping amount of foreign exchange reserve means the resource being left unused, so it may make output reduced, so the output that the relationship of the government whether keep foreign exchange reserve is,

$$
Y^{1}-Y=R i
$$

where $Y^{1}$ is the output of government does not hold foreign exchange reserve, $Y$ is the output of government hold foreign exchange reserve, where $R$ is foreign exchange reserve, $i$ is the opportunity cost for holding foreign exchange reserves.

Kelly, Michael G. (1970) designed the following government utility fuction.

$$
U=-a\left[E\left(Y^{1}\right)-E(Y)\right]^{2}-b[(Y)-E(Y)]^{2}
$$

\subsubsection{Considered the Inflation Made by the Chinese Government Buy Part Foreign Exchange If Company Earn and Design the Government Utility Function}

Based on Kelly, Michael G. (1970), consider the Chinese government buy part foreign exchange if company earn, it means that the Chinese government will increase supply of Ren-Min-Bi Yuan, and it will cause inflation. The inflation will cause disutility to government that is a negative government utility.

Combining with the outputting fluctuation, the foreign exchange reserves make the resource to be unused and lead to a negative social welfare, then design the following government utility function.

$$
U=-a\left[E\left(Y^{1}\right)-E(Y)\right]^{2}-b[(Y)-E(Y)-\beta \Delta \Pi]^{2}
$$

where $\beta>0$ is a coefficient, $\Pi$ is the inflation, $\Delta \Pi$ is change amount of inflation or increasing amount. $\left(E\left(Y^{1}\right)-E(Y)\right)$ is the average fluctuation outputs when government does not hold foreign exchange reserve and hold foreign exchange reserve, $((Y)-E(Y))$ is the fluctuation of outputs and average outputs.

$\Delta \Pi^{2}=\delta \Delta R^{2}, \delta>0$ is a coefficeint

$$
V(Y)=[(Y)-E(Y)]^{2}=S(Y)^{2}
$$

$$
\begin{aligned}
\beta \Delta \Pi^{2} & =\beta \delta \Delta R^{2}=\mathrm{d} \Delta R^{2}=\mathrm{d}[\Delta X-\Delta M]^{2} \\
& =\mathrm{d}[\Delta X(1-\Delta M / \Delta X)]^{2} \\
& =\mathrm{d}(X-E(X))^{2}(1-f)^{2}
\end{aligned}
$$

$\beta \delta=d>0$ in Equation (12)

$$
V(X)=(X-E(X))^{2}
$$

Put Equation (4) $V(Y)=E\left(\Delta Y^{2}\right)=g^{2} V(X)$ into Equation (13)

$$
V(X)=V(Y) / g^{2}=S(Y)^{2} / g^{2}
$$

Put Equations (9)-(13) into Equation (10), then gets the expectation efficacy function

$$
\begin{aligned}
E(U) & =-a\left[E\left(Y^{1}\right)-E(Y)\right]^{2} \\
& -b[(Y)-E(Y)-\beta \Delta \Pi]^{2} \\
& =-a i 2 E(R)^{2}-b V(Y) \\
& -d(X-E(X))^{2}(1-f)^{2} \\
& =-a i 2 E(R)^{2}-b V(Y)^{2}-d V(X)(1-f)^{2}
\end{aligned}
$$

Put Equation (14) in Equation (15), gives:

$$
E(U)=-a i^{2} E(R)^{2}-b S(Y)^{2}-d\left[S(Y)^{2} / g^{2}\right](1-f)^{2}
$$

\subsection{Demand Model of Optimal Foreign Exchange Reserves Based on Chinese Government Utility Maximization}

Choose variable $E(R)$ and $S(Y)$, and combine with the constraint condition Equation (8) and design the followinig $F$ fuction.

$$
\begin{gathered}
F=-a i^{2} E(R)^{2}-b S(Y)^{2}-d\left[S(Y)^{2} / g^{2}\right](1-f)^{2} \\
+\lambda\{E(R)-(c / e) 1 / 2[S(X)-m S(Y)]\} \\
\partial F / \partial E(R)=-2 a i^{2} E(R)+\lambda=0 \\
\partial F / \partial S(Y)=-2 b S(Y)-2 d\left[S(Y)^{2} / g^{2}\right](1-f)^{2} \\
+\lambda(c / e)^{1 / 2} m \\
=-2 b S(Y)-2 d S(Y)[(1-f) / g]^{2} \\
+\lambda(c / e)^{1 / 2} m \\
=0 \quad
\end{gathered}
$$

From Equation (16) gets:

$$
\lambda=2 \operatorname{ai} E(R)
$$

Put Equation (18) in Equation (17) 


$$
\begin{aligned}
& -2 b S(Y)-2 d S(Y)[(1-f) / g]^{2} \\
& +a i^{2} E(R)(c / e)^{1 / 2} m=0
\end{aligned}
$$

As a matter of convenience, arranges $h$ as the followings

$$
h=(c / e)^{1 / 2}
$$

From Equation (19) and Equation (20) gets

$$
S(Y)=\left[a i^{2} E(R) h m\right] /\left\{b+[(1-f) / g]^{2} d\right\}
$$

Put Equation (21) in Equation (8)

$$
\begin{aligned}
& E(R)= \\
& h\left\{S(X)-m\left\{a i^{2} E(R) h m /\left\{b+[(1-f) / g]^{2} d\right\}\right\}\right\}
\end{aligned}
$$

From Equation (22) gets

$$
\begin{aligned}
& E(R)= \\
& {[S(X)] /\left\{h^{-1}+\left(a i^{2} m^{2} h\right) /\left\{b+[(1-f) / g]^{2} d\right\}\right\}}
\end{aligned}
$$

Put $f=\mathrm{d} M / \mathrm{d} X=m g$ in Equation (23)

$$
\begin{aligned}
& E(R)= \\
& {[S(X)] /\left\{h^{-1}+\left(a i^{2} m^{2} h\right) /\left[b+\left(g^{-1}-m\right)^{2} d\right]\right\}}
\end{aligned}
$$

Because of $D 1=F_{E(R)^{2}}=-2 a i^{2}<0$
So

$$
\begin{aligned}
D 1 & =F E(R)^{2} F S(Y)^{2}-(F E(R) S(Y))^{2} \\
& =-2 a i^{2}\left[-2 b-2 d[(1-f) / g]^{2}\right]-0^{2}
\end{aligned}
$$

Conditions as above satisfied binary function approach maximum, that is the government expectation efficacy function $E(U)$ exist a maximum, the optimal foreign exchange reserves based on government utility maximization could fixed by Equation (24).

Be convenient order, let

$$
\begin{gathered}
k=h-1+\left(a i^{2} m^{2} h\right) /\left[b+\left(g^{-1}-m\right)^{2} d\right] \\
w=b+\left(g^{-1}-m\right)^{2} d
\end{gathered}
$$

\subsection{Analyze the Optimal Expectation Foreign Exchange Reserve to the Sensitivity of Variable and Parameter Based on Government Utility Maximization}

The foreign exchange reserve which government expectation utility maximization $E(U)$ exist a maximum is the optimal expectation foreign exchange reserve $E(R)$, to the sensitivity $\partial E(R) / \partial g$ of reaction coefficient $g=\mathrm{d} Y / \mathrm{d} X$ that income to export, approach the partial derivative.

$$
\begin{aligned}
& \partial E(R) / \partial g= \\
& {\left[-S(X) h a i^{2} m^{2} 2 d\left(g^{-1}-m\right) g^{-2}\right] / k^{2} w^{2}}
\end{aligned}
$$

When $g^{-1}-m>0$, that is $f=\mathrm{d} M / \mathrm{d} X=m g<1$

$$
\begin{aligned}
& \partial E(R) / \partial g= \\
& {\left[-S(X) h a i^{2} m^{2} 2 d\left(g^{-1}-m\right) g^{-2}\right] / k^{2} w^{2}<0}
\end{aligned}
$$

When $g^{-1}-m>0$, that is $f=\mathrm{d} M / \mathrm{d} X=m g>1$

$$
\begin{aligned}
& \partial E(R) / \partial g= \\
& {\left[-S(X) h a i^{2} m^{2} 2 d\left(g^{-1}-m\right) g^{-2}\right] / k^{2} w^{2}>0}
\end{aligned}
$$

When $g^{-1}-m=0$, that is $f=\mathrm{d} M / \mathrm{d} X=m g=1$

$$
\begin{aligned}
& \partial E(R) / \partial g= \\
& {\left[-S(X) h a i^{2} m^{2} 2 d\left(g^{-1}-m\right) g^{-2}\right] / k^{2} w^{2}=0}
\end{aligned}
$$

So the sensitivity $\partial E(R) / \partial g$ of reaction coefficient ( $g=\mathrm{d} Y / \mathrm{d} X)$ that optimal foreign exchange reserve to reaction coefficient that import to export is depend on the size of $f=m g$, that is depend on the size of the reaction coefficient $f=\mathrm{d} M / \mathrm{d} X$ that import to export.

The optimal foreign exchange reserve susceptibility $\partial E(R) / \partial m$ to the marginal propensity to import $(m=\mathrm{d} M / \mathrm{d} Y)$, approach the partial derivative.

$$
\begin{aligned}
& \partial E(R) / \partial m= \\
& \left\{-S(X) h 2 a i^{2} m^{2}\left[b+d / g^{-2}-(m d) / g\right]\right\} / k^{2} w^{2}
\end{aligned}
$$

When $b<\left[d\left(m-g^{-1}\right)\right] / g=[d(1-f)] / g^{2}$

$\partial E(R) / \partial m=$

$\left\{-S(X) h 2 a i^{2} m^{2}\left[b+d / g^{-2}-(m d) / g\right]\right\} / k^{2} w^{2}>0$

When $b>\left[d\left(m-g^{-1}\right)\right] / g=[d(1-f)] / g^{2}$

$\partial E(R) / \partial m=$

$\left\{-S(X) h 2 a i^{2} m^{2}\left[b+d / g^{-2}-(m d) / g\right]\right\} / k^{2} w^{2}<0$

When $b=\left[d\left(m-g^{-1}\right)\right] / g=[d(1-f)] / g^{2}$

$\partial E(R) / \partial m=$

$\left\{-S(X) h 2 a i^{2} m^{2}\left[b+d / g^{-2}-(m d) / g\right]\right\} / k^{2} w^{2}=0$

The optimal expectation foreign exchange reserve susceptibility $\partial E(R) / \partial S(X)$ to the export standard deviation $S(X)$, approach the partial derivative, 


$$
\partial E(R) / \partial S(X)=1 / k
$$

because $k=h^{-1}+\left(a i^{2} m^{2} h\right) / b+\left(g^{-1}-m\right)^{2} d$, so:

$$
\partial E(R) / \partial S(X)=1 / k>0
$$

The optimal expectation foreign exchange reserve susceptibility $\partial E(R) / \partial i$ to the opportunity cost for government holding foreign exchange reserves $i$, approach the partial derivative,

$$
\partial E(R) / \partial i=\left\{-2 S(X) h a i^{2} i\left[b+(1-f)^{2} d / g^{2}\right]\right\}<0
$$

\subsection{Brief Summaries}

The thesis finishes the following researches:

1) The author designs the government utility function when consider the China government buy part foreign exchange if company earn, it means that the China government will increase Ren-Min-Bi yuan, and it will cause inflation. The inflation will cause disutility to government; 2) The thesis gets the optimal foreign exchange reserves by Maximum the government utility.

\section{Unit Root Test and Cointegration Analysis for Demand Variable of Optimal Foreign Exchange Reserves Based on Government Utility Maximization}

This thesis takes the unit root test and cointegration analysis for demand variable optimal foreign exchange reserves based on government utility maximization.

\subsection{About Data and Express and Process for Data}

In order to discuss conveniently, the authors use as the following marks to express the different economic variable in this thesis. Dimension of $R, X 2, S(X), M, d M$ is 100 million US Dollar

$\mathrm{R}$ is the foreign exchange reserve in China

$E R$ is equal to exchange rate
$X 1$ is the export amount per year (Dimension of $\mathrm{R}, X 2$, $S(X), M, d M$ is 100 million RMB Dollars)

$X 2$ is the export amount per year

$d X 2$ is the export increasing amount per year

$E(X)$ is the average value of $X 2$

$S(X)$ is the absolute value of the deviation between the average value of $X 2$ and $X 2$

$d M$ is the import increasing amount per year

$Y 2$ is GDP $=Y 1 / \mathrm{ER}$

$d Y 2$ is the GDP increasing amount per year

$g=\mathrm{d} Y / \mathrm{d} X, g$ is the reaction factor from income to export, where $\mathrm{Y}$ is income

$i=y t 2-y r$ is the opportunity cost for holding foreign exchange reserves, using the difference between profit rate and the reserve earnings yield before capital tax in China to compotator.

$y t 2$ is the profit rate before capital tax in China.

$y r$ is the reserve earnings yield, using one year treasury bill rate-inflation rate in USA $y r=b r-i r$

$b r$ is one-year Treasury bill yield rate in USA.

$i r$ is the inflation in USA; take the yearly average inflation in USA as the standard.

The value of $\mathrm{m}, \mathrm{i}, \mathrm{g}$ be changed to the positive value when they are negative value by inserting reasonable value, so we use datas as Appendix Table 1 to analyze unit root ( In order to convenient for readers, shown M, Y2, $y t 2$, $b r, i r, y r=b r-i r, i=y t 2-y r$ in Appendix Table 2.

(The principle is, if the column datas $\mathrm{m}, \mathrm{g}$ are -0.001 , $-0.01,-1,-10,-100$, then change to $0.1,0.01,0.001$, $0.001,0.0001 .0 .0001,0.000001$; if the column data $\mathrm{i}$ is -0.001 , then change to 0.00001 )

\subsection{About the Unit Root Test for Variable}

LNR, LNSX, LNM, LNI, LNG, these variables' defining in several is

$$
\begin{aligned}
& L N R=L O G(R) ; L N S X=L O G(S X) \\
& L N M=L O G(m) ; L N I=L O G(i) ; L N G=L O G(g)
\end{aligned}
$$

That is, LNR, LNSX, LNM, LNI, LNG is the natural logarithm value of $R, S X, m, i, g$, from Figures 1(a) and (b). We can see that $L N R, L N S X, L N M, L N I, L N G$ these variables are very unstable.

Table 1. The results of cointegration test for $L N R, L N S X, L N M, L N I, L N G$.

\begin{tabular}{ccccc}
\hline Eigenvalue & Trace Statistics & $5 \%$ level critical value & 1\% level critical value & The null hypothesis: the amount of cointegration equation \\
\hline 0.744664 & 87.44357 & 68.52 & 76.07 & 0 ** \\
0.660712 & 54.67939 & 47.21 & 54.46 & be equal or less than $1^{* *}$ \\
0.557578 & 28.73762 & 29.68 & 35.65 & be equal or less than 2 \\
0.303918 & 9.165804 & 15.41 & 20.04 & be equal or less than 3 \\
0.019430 & 0.470908 & 3.76 & 6.65 & be equal or less than 4 \\
\hline
\end{tabular}

The upper results express that there are exist 2 cointegration equations with a $5 \%$ significant level. 
Table 2. The value of $A I C$ and $S C$ for $L N R, L N S X, L N M, L N I, L N G$ with $K$ equal to 2, 3, 4.

\begin{tabular}{|c|c|c|c|c|c|}
\hline$A I C$ and $S C$ & $L N R$ & LNSX & $L N M$ & $L N I$ & $L N G$ \\
\hline \multicolumn{6}{|c|}{ When $K=2$ the results as follows, } \\
\hline Akaike $A I C$ & 0.615183 & 2.000989 & 4.456350 & 3.251926 & 6.414522 \\
\hline Schwarz $S C$ & 1.155124 & 2.540930 & 4.996291 & 3.791867 & 6.954464 \\
\hline \multicolumn{6}{|c|}{ When $K=3$ the results as follows, } \\
\hline Akaike $A I C$ & -0.336246 & 2.073180 & 4.757156 & 3.469487 & 5.974624 \\
\hline Schwarz $S C$ & 0.453663 & 2.863089 & 5.547065 & 4.259396 & 6.764533 \\
\hline \multicolumn{6}{|c|}{ When $K=4$ the results as follows, } \\
\hline Akaike $A I C$ & -12.38870 & -4.499733 & -0.183613 & -3.185220 & 3.734113 \\
\hline Schwarz $S C$ & -11.34725 & -3.458283 & 0.857836 & -2.143770 & 4.775563 \\
\hline
\end{tabular}
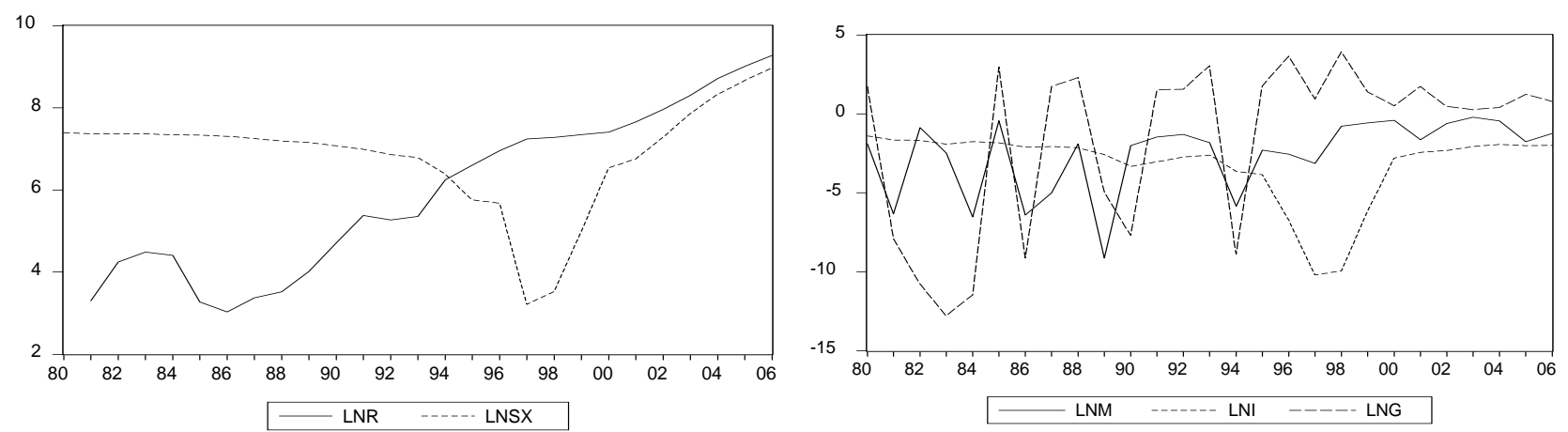

Figure 1. (a) LNR, LNSX; (b). LNM, LNI, and LNG.

\subsubsection{Unit Root Test for $L N R$}

Sequence number

ADF test

DW
1) $D(L N R)=0.09218+0.01466 \operatorname{LNR}(-1)+0.46569 D(\operatorname{LNR}(-1))-0.28970 D(L N R(-2))$ $(0.341475)(0.319634) * \quad(2.085069) \quad(-1.406102)$

2) $D(L N R, 2)=-0.52131 D(\operatorname{LNR}(-1))+0.12159 D(\operatorname{LNR}(-1), 2)-0.02565 D(\operatorname{LNR}(-2), 2)$

$$
(-2.052857) * \quad(0.506699)
$$

$(-0.121333)$

\subsubsection{Unit Root Test for $L N S X$}

Sequence number

ADF test

DW

1) $D(L N S X)=0.002402 \operatorname{LNSX}(-1)+0.324335 D(\operatorname{LNSX}(-1))-0.065271 D($ LNSX $(-2)) \quad 2.00$

$$
(0.108364) * \quad(1.479004) \quad(-0.295998)
$$

2) $D(\operatorname{LNSX}, 2)=-0.7834 D(\operatorname{LNS} X(-1))+0.1059 D(\operatorname{LNS} X(-1), 2)+0.0627 D(\operatorname{LNSX}(-2), 2)$

1.98

$$
(-2.485189)^{*} \quad(0.387888) \quad(0.277638)
$$

\subsubsection{Unit Root Test for $L N M$}

Sequence number

ADF test

DW

1) $D(L N M)=-0.143051 \operatorname{LNM}(-1)-0.835517 D(\operatorname{LNM}(-1))-0.539727 D(\operatorname{LNM}(-2))$

$$
(-0.971128)^{*} \quad(-4.473790) \quad(-3.287342)
$$

2) $D(L N M, 2)=-1.981791 D(\operatorname{LNM}(-1))+0.173656 D(\operatorname{LNM}(-1), 2)-0.19828 D(\operatorname{LNM}(-2), 2)$

$$
(-3.172415) * \quad(0.389723) \quad(-0.957421)
$$

\subsubsection{Unit root test for $L N G$}

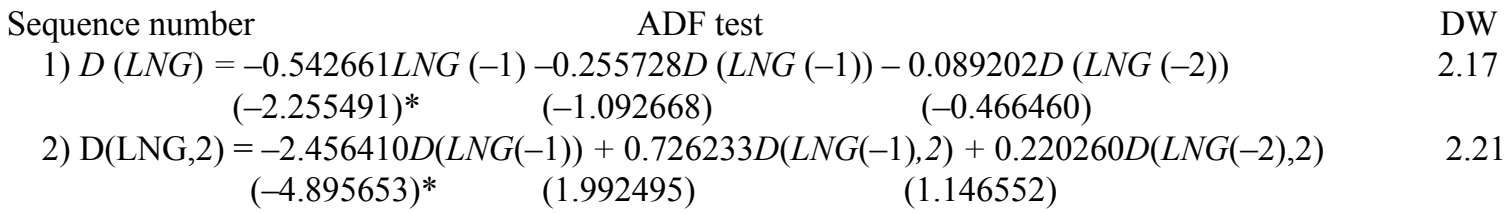




\subsubsection{Unit Root Test for $L N I$}

\begin{tabular}{|c|c|c|}
\hline Sequence number & ADF test & \\
\hline 1) $\begin{aligned} D(L N I)= & -0.040487 L N I(-1) \\
& (-0.738903)^{*}\end{aligned}$ & $\begin{array}{c}+0.815233 D(L N I(-1))-0.543165 D(L N I(-2)) \\
(4.669897)\end{array}$ & \\
\hline 2) $\begin{aligned} D(L N I, 2)= & -0.678647 D(L N I(-) \\
& (-2.764549)^{*}\end{aligned}$ & $\begin{array}{c}1))+0.566184 D(L N I(-1), 2)-0.119654 D(L N I(-2), 2) \\
(3.078573)\end{array}$ & 1.95 \\
\hline
\end{tabular}

\subsection{About the cointegration analysis for variable}

Although from Figures 1(a) and (b) we can see, $L N R$, $L N S X, L N M, L N I, L N G$, these variables are very stable, their first difference,such as DLNR, DLNSX, DLNM, $D L N I, D L N G$ are very stable, these five variables exist a similar change cycle, that exist cointegration relation, see to Figure 2

The results of cointegration test for $L N R, L N S X, L N M$, $L N I, L N G$ see to Table $\mathbf{1}$.

\subsection{Brief Summarizes}

Unit root test the nature logarithm of variables which the optimal foreign exchange reserves function include, the thesis find they are $\mathrm{I}(1)$,they exist co integration.

\section{Using VAR and VEC Model Analysis of the Equilibrium Foreign Exchange Reserves Demand Based on Chinese Data between 1985 and 2006}

This section finishes the following researches: VAR and VEC Model Analysis of the equilibrium Foreign Exchange Reserves Demand Based on Chinese data between 1985 and 2006.

\subsection{Choosing the Maximum Lag periods in VAR Model of Equilibrium Foreign Exchange Reserves}

\subsubsection{Using AIC and $S C$ to Choose $K$ Value in VAR Model}

Method 1, Using $A I C$ to choose $K$ value

$$
A I C=\log \left[\sum_{t=1}^{T} \hat{u}_{t}^{2} / T\right]+2 k / T
$$

$\hat{u}_{t}$ is the residual error, $T$ is the sample capacity; $k$ is the maximum delay section. The principle of choosing $K$ value is made $A I C$ value minimum through $k$ value increasing.

Method 2, Using SC to choose $K$ value

$$
S C=\log \left[\sum_{t=1}^{T} \hat{u}_{t}^{2} / T\right]+(k \log T) / T
$$

$\hat{u}_{t}$ is the residual error, $\mathrm{T}$ is the sample capacity; $k$ is the maximum delay section. The principle of choosing $K$ value is made $A I C$ value minimum through $\mathrm{k}$ value increasing.

Because of the limit of sample $T, K$ is equal to 4 at most, seeing from the change of AIC and SC, when $K=$ 4, the values of $A I C$ and $S C$ are minimum. So $K=4$ is the best choice with the limit of sample $T$.

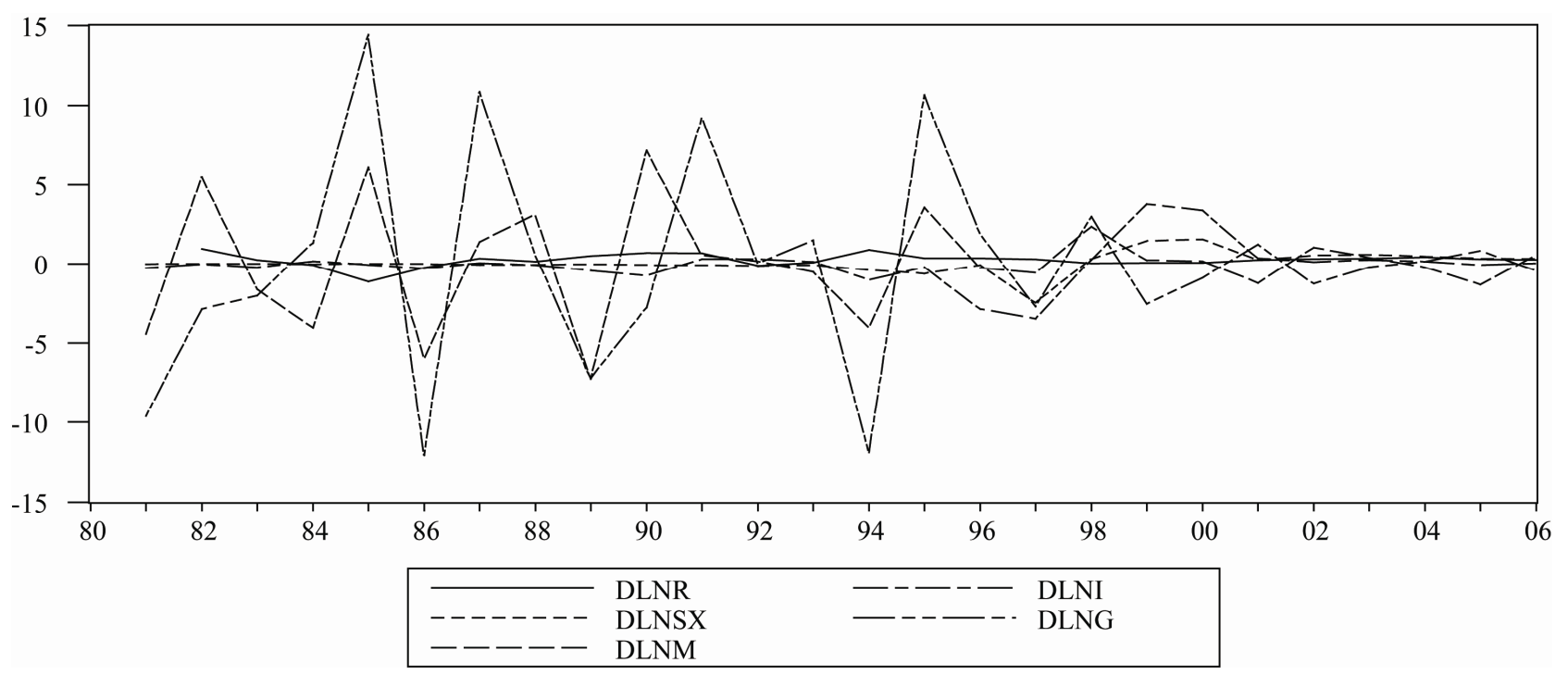

Figure 2. DLNR, DLNSX, DLNM, DLNI, DLNG using VAR Equation regressed and the actual results. 


\subsubsection{VAR Model of Equilibrium Foreign Exchange Reserves Demand Based on Chinese Data Between 1985 and 2006}

Because $K=4$ is the best choice, VAR model of equilibrium foreign exchange reserves demand based on Chinese data between 1985 and 2006 used $K=4$, when the variable delayed 4 sections, that is when $K=4$ the Equtions as follows,

$L N R=1.158208 * L N R(-1)-0.7595609028 * L N R(-2)$

$+1.275854675^{*} \operatorname{LNR}(-3)-0.41874649 * \operatorname{LNR}(-4)$

$-0.5326487006 * \operatorname{LNSX}(-1)+0.04889939537 * \operatorname{LNS} X(-2)$

$+0.272843226^{*} \operatorname{LNSX}(-3)-0.039302859 * \operatorname{LNSX}(-4)$

$-0.01712404005 * \operatorname{LNM}(-1)-0.1990991828 * \operatorname{LNM}(-2)$

$-0.1133346012 * L N M(-3)-0.0394768086 * \operatorname{LNM}(-4)$

$+0.3329742763 * L N I(-1)+0.1276036813 * \operatorname{LNI}(-2)$

$-0.1739915379 * L N I(-3)+0.0949172971 * L N I(-4)$

$+0.0309059384 * L N G(-1)+0.07122490394 * L N G(-2)$

$+0.05650023494 * L N G(-3)+0.01177553108 * L N G(-4)$

$+1.07792509$

$L N S X=-3.9380606 * \operatorname{LNR}(-1)+3.35668 * \operatorname{LNR}(-2)$

$-0.607910938 * \operatorname{LNR}(-3)+0.5289359612 * \operatorname{LNR}(-4)$

$+1.752410011 * \operatorname{LNSX}(-1)+0.7814465787 * \operatorname{LNS} X(-2)$

$-0.96916476 * \operatorname{LNSX}(-3)+0.3469152308 * \operatorname{LNSX}(-4)$

$+0.02346185581 * \operatorname{LNM}(-1)+0.380843381 * \operatorname{LNM}(-2)$

$+0.02583196853 * \operatorname{LNM}(-3)-0.1368834866 * \operatorname{LNM}(-4)$

$-0.2797186513 * \operatorname{LNI}(-1)-1.013477322 * \operatorname{LNI}(-2)$

$+1.247770225 * \operatorname{LNI}(-3)-0.455388757 * \operatorname{LNI}(-4)$

$-0.05458893085^{*} L N G(-1)-0.03839642266 * L N G(-2)$

$+0.1945562552 * L N G(-3)+0.2417625189 * L N G(-4)$

$-1.52559448$

$L N I=-8.618872 * L N R(-1)+9.4407164 * L N R(-2)$

$-6.7190925 * \operatorname{LNR}(-3)+3.102998318 * \operatorname{LNR}(-4)$

$+5.061829074 * \operatorname{LNSX}(-1)-1.173982425 * \operatorname{LNSX}(-2)$

$-1.455715567 * \operatorname{LNSX}(-3)+2.734477293 * \operatorname{LNSX}(-4)$

$+0.6480708563 * \operatorname{LNM}(-1)+1.557535337 * \operatorname{LNM}(-2)$

$+0.2412607597 * \operatorname{LNM}(-3)-0.09576680591 * \operatorname{LNM}(-4)$

$-2.139039105 * \operatorname{LNI}(-1)-0.4181240894 * \operatorname{LNI}(-2)$

$+2.005046131 * \operatorname{LNI}(-3)-1.968406804 * \operatorname{LNI}(-4)$

$-0.342939926 * L N G(-1)-0.1883294592 * L N G(-2)$

$+0.4212904271 * L N G(-3)+0.355278824 * L N G(-4)$

\section{$-21.58283256$}

$L N G=14.175261 * L N R(-1)-18.4748659 * L N R(-2)$

$+8.1032935 * \operatorname{LNR}(-3)+3.35161008 * \operatorname{LNR}(-4)$

$-10.54483977 * \operatorname{LNSX}(-1)+2.411978668 * \operatorname{LNSX}(-2)$

$+5.86210599 * \operatorname{LNSX}(-3)-2.55802967 * \operatorname{LNSX}(-4)$

$-0.0052018235 * \operatorname{LNM}(-1)-1.774668358 * \operatorname{LNM}(-2)$

$-1.075279662 * \operatorname{LNM}(-3)-1.741231895 * \operatorname{LNM}(-4)$

$+5.55427464 * L N I(-1)-0.9994607549 * \operatorname{LNI}(-2)$

$-2.685201432 * \operatorname{LNI}(-3)+1.629023047 * \operatorname{LNI}(-4)$

$-0.157488914 * L N G(-1)-0.186127449 * L N G(-2)$

$-0.8664866224 * L N G(-3)+0.02690099581 * L N G(-4)$

$-10.87342161$

Using $L N R$ equation in VAR equation set to forecast the foreign exchange reserve in China $(F R)$, the forecasting values of $F R$ and the actual values of $R$ are shown in Figure 3 and Table 3.

See from Table 3 the forecast error is very minor, from $0.02 \%$ to $0.1 \%$, and the forecasting is highly accurate, from $99.98 \%$ to $99.99 \%$.

\subsection{VEC Model Estimation of Equilibrium Foreign Exchange Reserves Demand Based on Chinese Data Between 1985 and 2006}

Because all the values $L N R, L N S X, L N M, L N I, L N G$ are I(1), also exist co integration, so exist a error correction model.

\subsubsection{Determining the Delay Section in the VEC Model of the Equilibrium Foreign Exchange Reserves Demand Based on the Chinese Data between 1985 and 2006}

Because when $K=1$

\begin{tabular}{cc}
\hline Akaike Information Criteria & 15.69124 \\
\hline Schwarz Criteria & 17.65466 \\
When $K=2$ & \\
Akaike Information Criteria & 13.59685 \\
Schwarz Criteria & 16.80585 \\
\hline
\end{tabular}

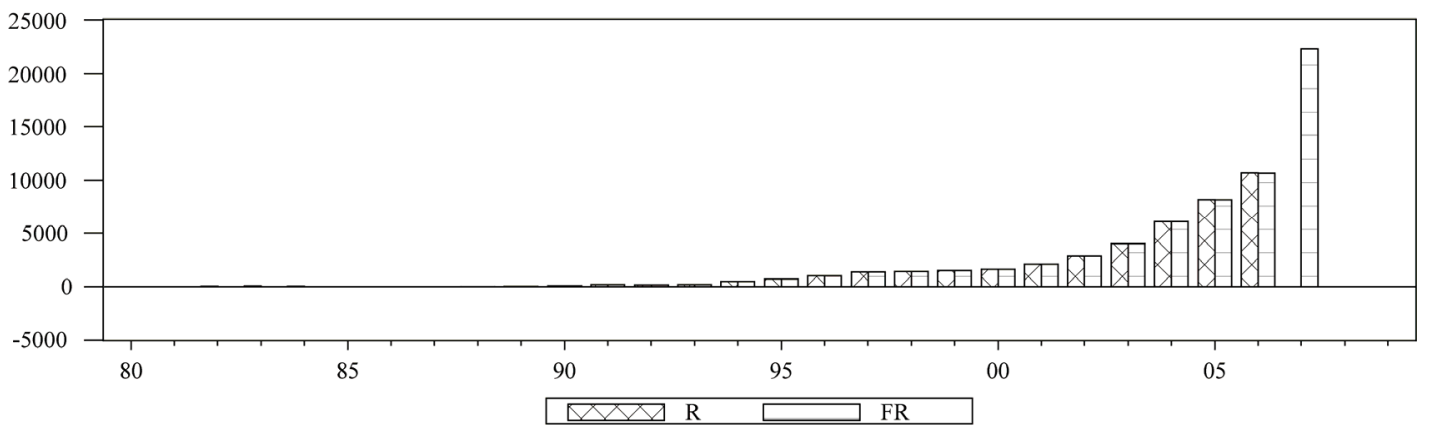

Figure 3. The forecasting values of $F R$ and the actual values of $\boldsymbol{R}$. 
Table 3. Forecast error between the value of $F R$ and $R$.

\begin{tabular}{|c|c|c|c|c|}
\hline obs & RESID & $R$ & $F R$ & $E S$ \\
\hline 1985 & 0.01 & 26.44 & 26.435 & 0.0002 \\
\hline 1986 & 0.01 & 20.72 & 20.709 & 0.0006 \\
\hline 1987 & 0.01 & 29.23 & 29.222 & 0.0003 \\
\hline 1988 & 0.01 & 33.72 & 33.71 & 0.0003 \\
\hline 1989 & 0.02 & 55.5 & 55.485 & 0.0003 \\
\hline 1990 & 0.07 & 110.93 & 110.86 & 0.0006 \\
\hline 1991 & 0.11 & 217.12 & 217.01 & 0.0005 \\
\hline 1992 & 0.12 & 194.43 & 194.31 & 0.0006 \\
\hline 1993 & 0.11 & 211.99 & 211.88 & 0.0005 \\
\hline 1994 & 0.31 & 516.2 & 515.89 & 0.0006 \\
\hline 1995 & 0.64 & 735.97 & 735.33 & 0.0009 \\
\hline 1996 & 0.72 & 1050.3 & 1049.6 & 0.0007 \\
\hline 1997 & 1.02 & 1398.9 & 1397.9 & 0.0007 \\
\hline 1998 & 1.09 & 1449.6 & 1448.5 & 0.0008 \\
\hline 1999 & 1.11 & 1546.8 & 1545.7 & 0.0007 \\
\hline 2000 & 1.39 & 1655.7 & 1654.3 & 0.0008 \\
\hline 2001 & 1.62 & 2121.7 & 2120.1 & 0.0008 \\
\hline 2002 & 2.16 & 2864.1 & 2861.9 & 0.0008 \\
\hline 2003 & 4.09 & 4032.5 & 4028.4 & 0.001 \\
\hline 2004 & 2.81 & 6099.3 & 6096.5 & 0.0005 \\
\hline 2005 & 12.3 & 8188.7 & 8176.4 & 0.0015 \\
\hline 2006 & 7.54 & 10663 & 10656 & 0.0007 \\
\hline 2007 & & & 22283 & \\
\hline
\end{tabular}

So $K=2$ is the best choice of cointegration equation and error correction model with the limit of sample capacity, gets the VEC model as follows,

\subsubsection{VEC Model Estimation Results of Equilibrium Foreign Exchange Reserves Demand Based on Chinese data between 1985 and 2006}

4.2.2.1. Delay section $K=1$

$D(L N R)=-0.02082643444 *(\operatorname{LNR}(-1)$

$-0.81557953 * \operatorname{LNSX}(-1)-0.91636494 * \operatorname{LNM}(-1)$

$+0.71058393 * \operatorname{LNI}(-1)-0.047428193 * L N G(-1)$

$-0.3588416363)+0.25008865 * D(L N R(-1))$

$+0.1427340478 * D(\operatorname{LNSX}(-1))$

$+0.02230181302 * D(L N M(-1))$

$-0.06450460302 * D(L N I(-1))$

$-0.02126208418 * D(L N G(-1))+0.1450919242$

$D(L N S X)=0.03164245422 *(L N R(-1)$

$-0.815579531 * \operatorname{LNSX}(-1)-0.9163649488^{*} \operatorname{LNM}(-1)$

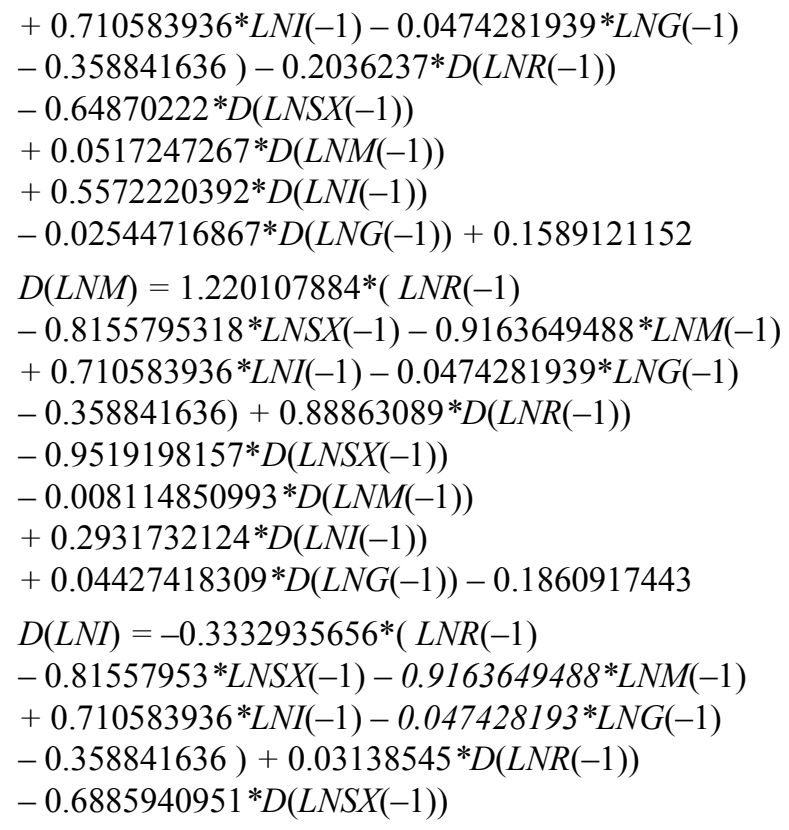




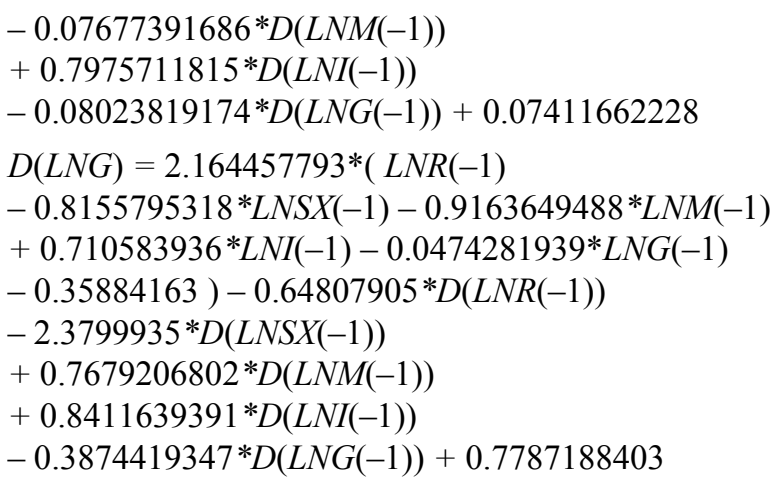

The long term equilibrium relation of these variables LNR, LNSX, LNM, LNI, LN are,

$\operatorname{LNR}(-1)=0.8155795318^{*} \operatorname{LNSX}(-1)$

$+0.9163649488 *$ LNM $(-1)-0.7105839363^{*}$ LNI $(-1)$

$+0.04742819394 * L N G(-1)+0.3588416363$

\subsubsection{Delay Section $K=2$}

$D(L N R)=0.0210919311 *(\operatorname{LNR}(-1)$

$-8.39646148 * \operatorname{LNSX}(-1)-6.53172328 * \operatorname{LNM}(-1)$

$+9.319611202 * L N I(-1)+5.921618915 * L N G(-1)$

$+72.52744886)-0.4199163335 * D(L N R(-1))$

$+0.02744055717 * D(L N R(-2))$

$+0.178363838 * D(\operatorname{LNSX}(-1))$

$-0.07798941 * D(L N S X(-2))+0.1637 * D(L N M(-1))$

$+0.100098 * D(L N M(-2))-0.210331 * D(L N I(-1))$

$+0.043212 * D(L N I(-2))-0.13208757 * D(L N G(-1))$

$-0.07503047391 * D(L N G(-2))+0.3559304786$

$D(L N S X)=0.009946085465 *(\operatorname{LNR}(-1)$

$-8.396461487 * \operatorname{LNSX}(-1)-6.531723289 * \operatorname{LNM}(-1)$

$+9.3196112 * L N I(-1)+5.921618915^{*} L N G(-1)$

$+72.52744886)-0.9757317399 * D(L N R(-1))$

$+0.2452650037 * D(L N R(-2))$

$+0.0633299 * D(\operatorname{LNSX}(-1))+0.622115 * D(\operatorname{LNSX}(-2))$

$+0.063976 * D(L N M(-1))+0.03197 * D(L N M(-2))$

$+0.34938 * D(L N I(-1))-0.553054 * D(L N I(-2))$

$-0.09832038718 * D(L N G(-1))$

$-0.0638524772 * D(L N G(-2))+0.2518144464$

$D(L N M)=-0.028990184 *(\operatorname{LNR}(-1)$

$-8.396461487 * \operatorname{LNSX}(-1)-6.531723289 * \operatorname{LNM}(-1)$

$+9.319611202 * \operatorname{LNI}(-1)+5.921618915^{*} L N G(-1)$

$+72.52744886)+3.9950447 * D(L N R(-1))$

$-0.9449371943 * D(L N R(-2))$

$+0.23898574 * D(\operatorname{LNSX}(-1))$

$+0.55443735 * D(\operatorname{LNS} X(-2))-1.12316 * D(\operatorname{LNM}(-1))$

$-0.6771437 * D(L N M(-2))$

$+0.3818 * D(L N I(-1))-0.830993 * D(L N I(-2))$

$+0.2355717803 * D(L N G(-1))$

$+0.09248289596 * D(L N G(-2))-0.6183532604$

$D(L N I)=-0.01178074236 *(\operatorname{LNR}(-1)$

$-8.3964614 * \operatorname{LNSX}(-1)-6.531723289 * \operatorname{LNM}(-1)$

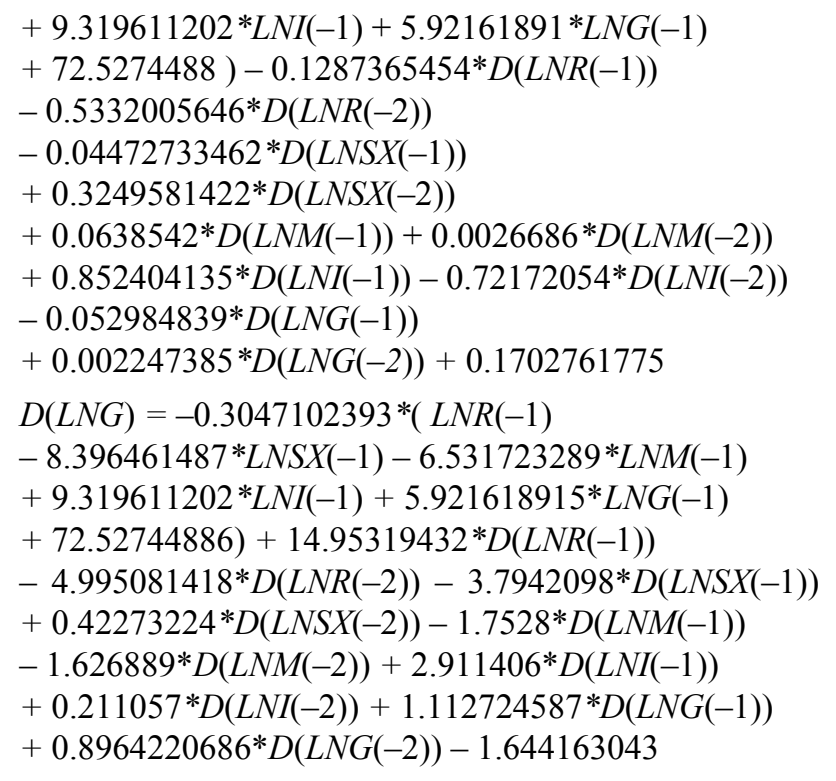

So the long term equilibrium relation of these variables $\operatorname{LNR}(-1), \operatorname{LNSX}(-1), \operatorname{LNM}(-1), \operatorname{LNI}(-1), \operatorname{LNG}(-1)$ are

$$
\begin{aligned}
& \operatorname{LNR}(-1)=8.396461487^{*} \operatorname{LNSX}(-1) \\
& +6.531723289^{*} \operatorname{LNM}(-1)-9.319611202 * \operatorname{LNI}(-1) \\
& -5.921618915^{*} \operatorname{LNG}(-1)-72.52744886
\end{aligned}
$$

The upper equation express that, the elasticity that the Chinese foreign exchange reserves to export standard deviation (SX) is 8.396461487 , it means that the export standard deviation increased $1 \%$, the foreign exchange reserves will increase $8.396461487 \%$. The elasticity that the Chinese foreign exchange reserves to the marginal propensity to import (m) is 6.531723289 , it means that the marginal propensity to import increased $1 \%$, the foreign exchange reserves will increase $6.531723289 \%$.It can be explained that, the marginal propensity to import means the unit output increased will caused more import, so more reserves are necessary for the need of import.

The elasticity of the Chinese foreign exchange reserves to the net opportunity cost $(i)^{1}$ is -9.319611202 , it means that the net opportunity cost of hold foreign exchange reserves increased $1 \%$; the Chinese foreign exchange reserves will reduce $9.319611202 \%$.

The elasticity between the foreign exchange reserves and the reaction coefficient of income to export is 5.921618915 , it means that the reaction coefficient of income to export increased $1 \%$, the foreign exchange reserves will reduce 5.921618915 .

It can be explained that, the reaction coefficient of income to export is $g$ increased, means that the increased unit export will lead to the unit output increase, and then increased the export lead to the foreign exchange re-

${ }^{1}$ net opportunity cost $=$ return rate of capital - return rate of Chinese foreign exchange reserves. 
serves increase, so the government should cut the holding foreign exchange reserves to make the government utility maximization.

3.2.2.3. Compared the Forecasting the Foreign Exchange Reserves with the Actual Foreign Exchange Reserves in the Long Term Equilibrium Relation with Delay Section $K=1$ and $K=2$

Suppose that FLLNR is the forecast of $L N R$ in the long term equilibrium relation with delay section $K=1$, gives the equation,

$F L L N R=0.8155795318 * \operatorname{LNSX}(-1)$

$+0.9163649488 * \operatorname{LNM}(-1)-0.7105839363 * L N I(-1)$

$+0.04742819394 * L N G(-1)+0.3588416363$

$F L R$ is the forecast of $R$ in long term equilibrium rela- tion, gives the equation,

$F L R=2.718^{\wedge} F L L N R$

Suppose FLLNR2 is the forecast of $L N R$ in long term equilibrium relation with delay section $K=2$, gives the equation,

FLLNR2 $=8.396461487 * \operatorname{LNS} X(-1)$

$+6.531723289 * \operatorname{LNM}(-1)$

$-9.319611202 * \operatorname{LNI}(-1)$

$-5.921618915^{*} L N G(-1)$

$-72.52744886$

$F L R 2$ is the forecast of $L N R$ in long term equilibrium relation with delay section $K=2$, gives the equation, FLR2 $=2.718^{\wedge}$ FLLNR

The results of forecasts are shown in Table 4 and Figure 4.

Table 4. The values comparing between the forecasting foreign exchange reserves and Actual foreign exchange reserves in long term equilibrium relation with delay section $K=1$ and $K=2$.

\begin{tabular}{|c|c|c|c|c|c|c|}
\hline ar & $R$ & $F L R$ & FLR2 & RESID & $D R$ & $R / F L R$ \\
\hline 1981 & 27.08 & 304.1448779 & 304.1448779 & -277.1 & -0.911 & 0.089 \\
\hline 1983 & 89.01 & 520.8666099 & 520.8666099 & -431.9 & -0.829 & 0.1709 \\
\hline 1984 & 82.2 & 127.0019411 & 127.0019411 & -44.8 & -0.353 & 0.6472 \\
\hline 1985 & 26.44 & 2.931360374 & 2.931360374 & 23.509 & 8.0197 & 9.0197 \\
\hline 1986 & 20.72 & 1598.467981 & 1598.467981 & -1578 & -0.987 & 0.013 \\
\hline 1987 & 29.23 & 4.615698492 & 4.615698492 & 24.614 & 5.3327 & 6.3327 \\
\hline 1988 & 33.72 & 25.47169536 & 25.47169536 & 8.2483 & 0.3238 & 1.3238 \\
\hline 1989 & 55.5 & 455.7770815 & 455.7770815 & -400.3 & -0.878 & 0.1218 \\
\hline 1991 & 217.12 & 539.6117699 & 539.6117699 & -322.5 & -0.598 & 0.4024 \\
\hline 1992 & 194.43 & 1037.334284 & 1037.334284 & -842.9 & -0.813 & 0.1874 \\
\hline 1993 & 211.99 & 886.7690989 & 886.7690989 & -674.8 & -0.761 & 0.2391 \\
\hline 1994 & 516.2 & 507.0328202 & 507.0328202 & 9.1672 & 0.0181 & 1.0181 \\
\hline 1995 & 735.97 & 10.75360771 & 10.75360771 & 725.22 & 67.439 & 68.439 \\
\hline 1996 & 1050.29 & 320.0219763 & 320.0219763 & 730.27 & 2.2819 & 3.2819 \\
\hline 1997 & 1398.9 & 1991.527008 & 1991.527008 & -592.6 & -0.298 & 0.7024 \\
\hline 1998 & 1449.6 & 1641.464691 & 1641.464691 & -191.9 & -0.117 & 0.8831 \\
\hline 1999 & 1546.8 & 17435.01253 & 17435.01253 & -15888 & -0.911 & 0.0887 \\
\hline 2000 & 1655.7 & 4232.041229 & 4232.041229 & -2576 & -0.609 & 0.3912 \\
\hline 2002 & 2864.1 & 487.0255929 & 487.0255929 & 2377.1 & 4.8808 & 5.8808 \\
\hline 2003 & 4032.5 & 1658.261504 & 1658.261504 & 2374.2 & 1.4318 & 2.4318 \\
\hline 2004 & 6099.3 & 3153.68506 & 3153.68506 & 2945.6 & 0.934 & 1.934 \\
\hline 2005 & 8188.7 & 3401.096381 & 3401.096381 & 4787.6 & 1.4077 & 2.4077 \\
\hline 2006 & 10663.4 & 1489.350917 & 1489.350917 & 9174 & 6.1598 & 7.1598 \\
\hline
\end{tabular}




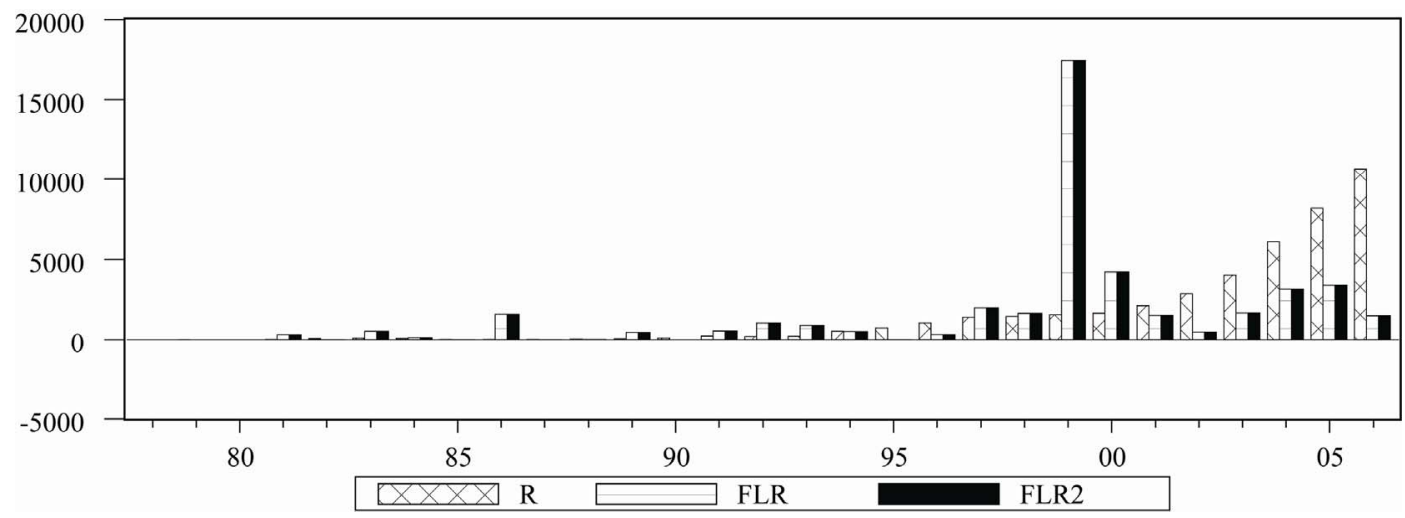

Figure 4. The values comparing between the forecasting foreign exchange reserves and Actual foreign exchange reserves in long term equilibrium relation with delay section $K=1$ and $K=2$.

I analyzed the Table 4. to find that: 1) The values of forecasting foreign exchange reserves in long term equilibrium relation with either delay section $K=1$ or $K=2$ are the same; 2) The ratio $R / F L R$ is equal to 1 express that the values of actual foreign exchange reserve and long-term equilibrium are the same. If it less than 1 , it express that the actual value is less than the long-term equilibrium. If it more than 1 , it express that the actual value is bigger than the long-term equilibrium; 3) From Table 4 we can find that the actual foreign exchange reserves bigger than the long-term equilibrium in 1982, $1985,1987,1990,1995,2002,2006$, and it is steady basically in 1994. The value of actual foreign exchange reserves is much bigger than the long-term equilibrium in these years 1982, 1990, 1995. Because the actual value is much bigger than the long-term equilibrium in 1990, The situation supply basis for Ren-Min-Bi exchange rate reform of China in 1994, Ren-Min-Bi exchange rate select one kind of exchange rate and supervisory floating exchange rate institution.Because the actual value is much bigger than the long-term equilibrium in 1995, the situation supply basis for Ren-Min-Bi free exchange under current account in 1996; 4)From Figure 4 we can see that the Chinese actual foreign exchange reserves are bigger than the long-term equilibrium foreign exchange reserves in 1982, 1985, 1987, 1990, 1995, 2002, 2006. The Chinese actual foreign exchange reserves are bigger than the long-term equilibrium foreign exchange reserves in 1982, 1990, 1995. They are nearly equal in 1994. The Chinese actual foreign exchange reserves are smaller than the long-term equilibrium foreign exchange reserves in 1981, 1986, 1999. The Chinese actual foreign exchange reserves are smaller than the long-term equilibrium foreign exchange reserves in 1999 for weak world economy.

This section chooses the VAR Regress finds the fitted value and actual value of foreign exchange reserves is nearly equal within $99.8 \%$. Finally it gets the long term equilibrium relation of the nature logarithm of variables by VEC model, which are foreign exchange reserves, standard error of export, marginal propensity to import, the opportunity cost for foreign exchange reserves, marginal output to export.

\section{Summarizes for This thesis}

The thesis finishes the following researches:

1) The author designs the government utility function when consider the China government buy part foreign exchange if company earn, it means that the China government will increase Ren-Min-Bi yuan, and it will cause inflation. The inflation will cause disutility to government.

2) The thesis gets the optimal foreign exchange reserves by Maximum the government utility.

3) Unit root test the nature logarithm of variables which the optimal foreign exchange reserves function include, the thesis find they are I(1),they exist co integration.

4) $V A R$ Regress finds the fitted value and actual value of foreign exchange reserves is nearly equal within $99.8 \%$.

5) The thesis gets the long term equilibrium relation of the nature logarithm of variables by VEC model, which are foreign exchange reserves, standard error of export, marginal propensity to import, the opportunity cost for foreign exchange reserves, marginal output to export.

6) The Chinese actual foreign exchange reserves are bigger than the long-term equilibrium foreign exchange reserves in 1982,1985,1987,1990,1995,2002,2006. The Chinese actual foreign exchange reserves are more bigger than the long-term equilibrium foreign exchange reserves in 1982, 1990, 1995.They are nearly equal in 1994. The Chinese actual foreign exchange reserves are smaller than the long-term equilibrium foreign exchange reserves in 1981, 1986, 1999. The Chinese actual foreign exchange reserves are smaller than the long-term equilib- 
rium foreign exchange reserves in 1999 for weak world economy.

Different from the Kelly, Michael G. (1970) [3], Kelly, Michael G. (1970) designed the government utility function without considering the China government buy part foreign exchange if company earn, it means that the China government will increase Ren-Min-Bi yuan, and it will cause inflation. The inflation will cause disutility to government. Finally it gets the optimal fuction, we can find through the sample data about 46 countries from 1953 to 1965 , (1) the government-holding foreign exchange reserves has positive correlation with the export standard error, (2) it has positive correlation with the average propensity to import [3].

This thesis designed the government utility function when consider the China government buy part foreign exchange if company earn, it means that the China government will increase Ren-Min-Bi yuan, and it will cause inflation. The inflation will cause disutility to government. Finally it gets the optimal fuction, using the sample datas in China 1980-2006 and VEC we can find: 1) The government-holding foreign exchange reserves has positive correlation with the export standard error; 2) It has positive correlation with the marginal propensity to import. The optimal fuction, data and regression method are all different, but all have the positive correlation between the foreign exchange reserves and export standard error, also is consonant with the results about the marginal propensity to import basically.

Different from Guobo Huang (1995), Guobo Huang (1995) collected the correlative economic datas from 1980 to 1990 in China, using ECM based on the quarterly datas to research the international reserves scale and discovered that: 1) The Chinese foreign exchange reserve has the negative correlation with import, that is when the import increased the foreign exchange reserves will reduce; 2 ) it has negative correlation with average propensity to import, that is when the average propensity to import increased the foreign exchange reserves will reduce. The thesis find that the elasticity that the Chinese foreign exchange reserves to the marginal propensity to import (m) is 6.531723289 , it means that the marginal propensity to import increased $1 \%$, the foreign exchange reserves will increase $6.531723289 \%$.It can be explained that, the marginal propensity to import means the unit output increased will caused more import, so more reserves are necessary for the need of import.

\section{Acknowledgements}

I would like to thank reviewer for their opinions, and thank proffessor Yuding Yu.

\section{References}

[1] H. R. Heller, "Optimal International Reserves," The Economic Journal, Vol. 76, No. 302, 1966, pp. 296-308.

[2] P. B. Clark, "Optimum International Reserves and the Speed of Adjustment," Journal of Political Economy, Vol. 78, No. 2, pp. 356-376.

[3] M. G. Kelly, "The Demand for International Reserves," American Economic Review, Vol. 60, No. 4, pp. 655-667.

[4] G. B. Huang, "Modeling China's Demand for International Reserves," Applied Financial Economics, Vol. 5, No. 5, pp. 357-366. doi:10.1080/758522763

[5] Y. D. Yu, "Some Problems on Foreign Exchange Reserves and International Balances," World Economics and Polics, No. 10, 1997, pp.18-23.

[6] J. Wu, "The Analysis and Affirmation of the China Foreign Exchange Reserves," Economy Research Journal, Vol. 33, No. 6, 1998, pp. 20-29.

[7] C. M. Xu, "The Reality of the Demand of the Foreign Exchange Reserves in China," Quantitative and Technical Economics, 2001, No. 12, pp. 101-103.

[8] M. Victoria, "Getting out from between a Rock and a Hard Place: Can China Use Its Foreign Exchange Reserves to Save Its Banks?" Journal of International Financial Markets, Institutions and Money, Vol. 16, No. 4, 2006, pp. 345-354.

[9] M. Ramachandran, "On the Upsurge of Foreign Exchange Reserves in India," Journal of Policy Modeling, Vol. 28, No. 7, 2006, pp. 797-809. doi:10.1016/j.jpolmod.2006.04.006

[10] K. Adnan and D. Ayhan, "Foreign Exchange Reserves and Exchange Rates in Turkey: Structural Breaks, Unit Roots and Cointegration," Economic Modelling, Vol. 25, No. 1, 2008, pp. 83-92.

[11] V. Pontines and R. S. Rajan, "Foreign Exchange Market Intervention and Reserve Accumulation in Emerging Asia: Is there Evidence of Fear of Appreciation?" Economics Letters, Vol. 111, No. 3, 2011, pp. 252- 255. doi:10.1016/j.econmod.2007.04.010 


\section{Appendix}

Table 1. The value of $\mathrm{m}, \mathrm{g}$, $\mathrm{i}$ after interpolation method estimate and Smoothing.

\begin{tabular}{|c|c|c|c|c|c|c|c|c|c|}
\hline$t$ & $R$ & $E R$ & $X 2$ & $S(X)$ & $M$ & $d M$ & $M=\mathrm{d} M / \mathrm{d} Y 2$ & $G=\mathrm{d} Y 2 / \mathrm{d} X 2$ & $i=y t 2-y r$ \\
\hline 1980 & -12.96 & 1.54 & 182.7 & 1620.28 & 192.9 & -27.3 & 0.14923 & 5.625417 & 0.2472 \\
\hline 1981 & 27.08 & 1.74 & 220.1 & 1582.88 & 213.9 & 21 & 0.001775 & 0.000372068 & 0.19 \\
\hline 1982 & 69.89 & 1.94 & 223.2 & 1579.78 & 274.1 & 60.2 & 0.418353 & 0.0000210503 & 0.1848 \\
\hline 1983 & 89.01 & 1.99 & 222.3 & 1580.68 & 422.5 & 148.4 & 0.083026 & 0.0000028103 & 0.1464 \\
\hline 1984 & 82.2 & 2.79 & 261.4 & 1541.58 & 429 & 6.5 & 0.0014615 & 0.0000105348 & 0.1708 \\
\hline 1985 & 26.44 & 3.2 & 273.5 & 1529.48 & 432.2 & 3.2 & 0.642079 & 19.10117 & 0.1595 \\
\hline 1986 & 20.72 & 3.72 & 309.4 & 1493.58 & 552.7 & 120.5 & 0.0016571 & 0.00010926 & 0.1195 \\
\hline 1987 & 29.23 & 3.72 & 394.4 & 1408.58 & 591.4 & 38.7 & 0.006675 & 5.640101 & 0.1256 \\
\hline 1988 & 33.72 & 3.72 & 475.2 & 1327.78 & 533.5 & -57.9 & 0.150211 & 9.928271 & 0.1166 \\
\hline 1989 & 55.5 & 4.24 & 525.4 & 1277.58 & 637.9 & 104.4 & 0.000107067 & 0.0072003 & 0.0757 \\
\hline 1990 & 110.93 & 5.22 & 620.9 & 1182.08 & 805.9 & 168 & 0.134211 & 0.000451739 & 0.0357 \\
\hline 1991 & 217.12 & 5.41 & 719.1 & 1083.88 & 1039.6 & 233.7 & 0.232027 & 4.581959 & 0.0483 \\
\hline 1992 & 194.43 & 5.8 & 849.4 & 953.58 & 1156.2 & 116.6 & 0.272804 & 4.726228 & 0.0642 \\
\hline 1993 & 211.99 & 5.81 & 917.4 & 885.58 & 1320.8 & 164.6 & 0.162339 & 21.17035 & 0.0733 \\
\hline 1994 & 516.2 & 8.49 & 1210.1 & 592.88 & 1388.3 & 67.5 & 0.0028822 & 0.000138212 & 0.0261 \\
\hline 1995 & 735.97 & 8.32 & 1487.8 & 315.18 & 1423.7 & 35.4 & 0.100987 & 5.869338 & 0.0213 \\
\hline 1996 & 1050.29 & 8.3 & 1510.5 & 292.48 & 1402.4 & -21.3 & 0.077414 & 38.41112 & 0.0012 \\
\hline 1997 & 1398.9 & 8.28 & 1827.9 & 24.92 & 1657 & 254.6 & 0.043478 & 2.565218 & 0.000037 \\
\hline 1998 & 1449.6 & 8.28 & 1837.1 & 34.12 & 2250.9 & 593.9 & 0.4542 & 50.96881 & 0.000048 \\
\hline 1999 & 1546.8 & 8.28 & 1949.3 & 146.32 & 2435.5 & 184.6 & 0.56634 & 4.006712 & 0.0021 \\
\hline 2000 & 1655.7 & 8.28 & 2492 & 689.02 & 2951.7 & 516.2 & 0.664472 & 1.646936 & 0.0606 \\
\hline 2001 & 2121.7 & 8.28 & 2661 & 858.02 & 4127.6 & 1175.9 & 0.194794 & 5.607509 & 0.0866 \\
\hline 2002 & 2864.1 & 8.28 & 3256 & 1453.02 & 5612.3 & 1484.7 & 0.543956 & 1.594913 & 0.0977 \\
\hline 2003 & 4032.5 & 8.28 & 4382.3 & 2579.32 & 6599.5 & 987.2 & 0.806024 & 1.295293 & 0.1251 \\
\hline 2004 & 6099.3 & 8.28 & 5933.3 & 4130.32 & 7916 & 1316.5 & 0.63818 & 1.499975 & 0.1443 \\
\hline 2005 & 8188.7 & 8.19 & 7619.5 & 5816.52 & & & 0.17097 & 3.424325 & 0.1321 \\
\hline 2006 & 10663.4 & 7.81 & 9691 & 7888.02 & & & 0.289261 & 2.197084 & 0.1354 \\
\hline
\end{tabular}

Note: Dimension of R, X2, S (X), M, dM is 100 million US Dollar; R is Chinese Foreign Exchange Reserves; ER is the exchange rate; it is Renminbi (RMB)'s amount of a dollar, which comes from The Chinese State Administration of Foreign Exchange website http://www.safe.gov.cn/ model safe en/index.jsp?id = 6; And the some data of the table come from: Zhang Xiaopu (2001), Study on Renminbi (RMB)'s equilibrium rate of exchange, China Financial Publishing House, Jan.2001. X2 is the export amount per year; dX2 is the export increasing amount per year; E (X) is the average value of X2; S (X) is the absolute value of the deviation between the average value of X2 and X2; $\mathrm{M}$ is the import amount per year; $\mathrm{dM}$ is the import increasing amount per year; Y1 is GDP; Dimension of $\mathrm{Y} 1$ is 100 million Renminbi (RMB); Y2 is GDP =Y1/ER, ER is Renminbi (RMB)'s amount of a dollar; dY2 is the GDP increasing amount per year; $\mathrm{g}=\mathrm{dY} / \mathrm{dX}, \mathrm{g}$ is the reaction factor from income to export, where $\mathrm{Y}$ is income; $\mathrm{i}=\mathrm{yt}$ 2-yr is the opportunity cost for holding foreign exchange reserves, using the difference between profit rate and the reserve earnings yield before capital tax in China to compotator. yt2 is the profit rate before capital tax in China.yt2 come from the following thesis:Guoqing Song, Feng Lu, Jie Tang, Hongyan Zhao, Liu Liu (2007), Value on the yield rate of Chinese Capital (1978-2006), China Center for Economic Research (CCER) at Peking University Working paper Series No.C 2007002 (writer finished: Feng Lu)(calculated from the Working paper Series No.C 2007002); yr is the reserve earnings yield, using one year treasury bill rate-inflation rate in USA yr=br-ir; br is one-year Treasury bill yield rate in USA. Please see the following website;

http://www.federalreserve.gov/datadownload/Download.aspx?rel=H15\&series $=$ bf17364827e $38702 \mathrm{~b} 42 \mathrm{a} 58 \mathrm{cf} 8 \mathrm{eaa} 3 \mathrm{f} 78 \&$ lastObs $=\&$ from $=\&$ to $=\&$ filetype $=\mathrm{csv} \&$ la bel=include\&layout=seriescolumn\&type=package; ir is the inflation in USA, take the yearly average inflation in USA as the standard. Please see the following web-page: http://inflationdata.com/Inflation/Inflation_Rate/ HistoricalInflation.aspx. 
Table 2. The actual value of $M, Y 2, y t 2, b r, i r, y r=b r-i r, i=y t 2-y r$.

\begin{tabular}{|c|c|c|c|c|c|c|c|c|c|c|}
\hline$t$ & $Y 1$ & $Y 2$ & $\mathrm{~d} Y 2$ & $M=\mathrm{d} M / \mathrm{d} Y 2$ & $g=\mathrm{d} Y 2 / \mathrm{d} X$ & $y t 2$ & $b r$ & $i r$ & $y r$ & $i$ \\
\hline 1980 & 4517.8 & 2933.636 & 259.3317 & 0.14923 & 5.625417 & $25.00 \%$ & $13.86 \%$ & $13.58 \%$ & $0.28 \%$ & 0.2472 \\
\hline 1981 & 4862.4 & 2794.483 & -139.154 & -0.1775 & -3.72068 & $22.00 \%$ & $13.35 \%$ & $10.35 \%$ & $3.00 \%$ & 0.19 \\
\hline 1982 & 5294.7 & 2729.227 & -65.256 & 0.418353 & -21.0503 & $21.00 \%$ & $8.68 \%$ & $6.16 \%$ & $2.52 \%$ & 0.1848 \\
\hline 1983 & 5934.5 & 2982.161 & 252.934 & 0.083026 & -281.038 & $21.50 \%$ & $10.08 \%$ & $3.22 \%$ & $6.86 \%$ & 0.1464 \\
\hline 1984 & 7171 & 2570.251 & -411.91 & -0.14615 & -10.5348 & $22.00 \%$ & $9.22 \%$ & $4.30 \%$ & $4.92 \%$ & 0.1708 \\
\hline 1985 & 8964.4 & 2801.375 & 231.1241 & 0.642079 & 19.10117 & $20.00 \%$ & $7.60 \%$ & $3.55 \%$ & $4.05 \%$ & 0.1595 \\
\hline 1986 & 10275.2 & 2762.151 & -39.2245 & -0.16571 & -1.0926 & $16.00 \%$ & $5.95 \%$ & $1.90 \%$ & $4.05 \%$ & 0.1195 \\
\hline 1987 & 12058.6 & 3241.559 & 479.4086 & 0.006675 & 5.640101 & $16.00 \%$ & $7.10 \%$ & $3.66 \%$ & $3.44 \%$ & 0.1256 \\
\hline 1988 & 15042.8 & 4043.763 & 802.2043 & 0.150211 & 9.928271 & $16.60 \%$ & $9.02 \%$ & $4.08 \%$ & $4.94 \%$ & 0.1166 \\
\hline 1989 & 16992.3 & 4007.618 & -36.1455 & -1.07067 & -0.72003 & $10.50 \%$ & $7.76 \%$ & $4.83 \%$ & $2.93 \%$ & 0.0757 \\
\hline 1990 & 18667.8 & 3576.207 & -431.411 & 0.134211 & -4.51739 & $5.00 \%$ & $6.82 \%$ & $5.39 \%$ & $1.43 \%$ & 0.0357 \\
\hline 1991 & 21781.5 & 4026.155 & 449.9484 & 0.232027 & 4.581959 & $4.70 \%$ & $4.12 \%$ & $4.25 \%$ & $-0.13 \%$ & 0.0483 \\
\hline 1992 & 26923.5 & 4641.983 & 615.8275 & 0.272804 & 4.726228 & $7.00 \%$ & $3.61 \%$ & $3.03 \%$ & $0.58 \%$ & 0.0642 \\
\hline 1993 & 35333.9 & 6081.566 & 1439.584 & 0.162339 & 21.17035 & $8.00 \%$ & $3.63 \%$ & $2.96 \%$ & $0.67 \%$ & 0.0733 \\
\hline 1994 & 48197.9 & 5677.02 & -404.546 & -0.28822 & -1.38212 & $7.20 \%$ & $7.20 \%$ & $2.61 \%$ & $4.59 \%$ & 0.0261 \\
\hline 1995 & 60793.7 & 7306.935 & 1629.915 & 0.100987 & 5.869338 & $4.50 \%$ & $5.18 \%$ & $2.81 \%$ & $2.37 \%$ & 0.0213 \\
\hline 1996 & 67884.6 & 8178.867 & 871.9324 & 0.077414 & 38.41112 & $2.70 \%$ & $5.51 \%$ & $2.93 \%$ & $2.58 \%$ & 0.0012 \\
\hline 1997 & 74462.6 & 8993.068 & 814.2002 & 0.043478 & 2.565218 & $2.80 \%$ & $5.51 \%$ & $2.34 \%$ & $3.17 \%$ & -0.0037 \\
\hline 1998 & 78345.2 & 9461.981 & 468.913 & -0.04542 & 50.96881 & $2.50 \%$ & $4.53 \%$ & $1.55 \%$ & $2.98 \%$ & -0.0048 \\
\hline 1999 & 82067.5 & 9911.534 & 449.5531 & 0.56634 & 4.006712 & $4.00 \%$ & $5.98 \%$ & $2.19 \%$ & $3.79 \%$ & 0.0021 \\
\hline 2000 & 89468.1 & 10805.33 & 893.7923 & 0.664472 & 1.646936 & $8.00 \%$ & $5.32 \%$ & $3.38 \%$ & $1.94 \%$ & 0.0606 \\
\hline 2001 & 97314.8 & 11753 & 947.6691 & 0.194794 & 5.607509 & $8.00 \%$ & $2.17 \%$ & $2.83 \%$ & $-0.66 \%$ & 0.0866 \\
\hline 2002 & 105172.3 & 12701.97 & 948.9734 & 0.543956 & 1.594913 & $9.50 \%$ & $1.32 \%$ & $1.59 \%$ & $-0.27 \%$ & 0.0977 \\
\hline 2003 & 117251.9 & 14160.86 & 1458.889 & 0.806024 & 1.295293 & $11.50 \%$ & $1.26 \%$ & $2.27 \%$ & $-1.01 \%$ & 0.1251 \\
\hline 2004 & 136515 & 16487.32 & 2326.461 & 0.63818 & 1.499975 & $14.50 \%$ & $2.75 \%$ & $2.68 \%$ & $0.07 \%$ & 0.1443 \\
\hline 2005 & 182321 & 22261.42 & 5774.098 & 0.17097 & 3.424325 & $15.20 \%$ & $4.38 \%$ & $2.39 \%$ & $1.99 \%$ & 0.1321 \\
\hline 2006 & 209407 & 26812.68 & 4551.26 & 0.289261 & 2.197084 & $15.30 \%$ & $5 \%$ & $3.24 \%$ & $1.76 \%$ & 0.1354 \\
\hline
\end{tabular}

Note: 1 . Y2 is GDP =Y1/ER, ER is Renminbi (RMB)'s amount of a dollar, ER come from Appendix Table 1; The meaning of Symbol Y1,dY2 and so on are the same from Appendix Table 1; Dimension of Y1 is 100 million Renminbi (RMB), Dimension of Y2,DY2 is 100 million US Dollar. 
Table 3. The structure of chinese foreign exchange reserves.

\begin{tabular}{|c|c|c|c|c|c|c|c|}
\hline YEAR & $\mathrm{AFR}^{\#}$ & $\mathrm{GR}^{\Omega}$ & $\mathrm{GP}^{\Omega \Omega}$ & $\mathrm{GV}^{\Omega \Omega \Omega}$ & GV/ AFR & $\operatorname{SDRs}^{\Psi}$ & $\mathrm{SDR}_{\mathrm{S}} / \mathrm{AFR}$ \\
\hline 1980 & -12.96 & 1280 & 600.71 & 76.89088 & -5.93294 & NA & \\
\hline 1981 & 27.08 & 1267 & 464.76 & 58.88509 & 2.174486 & NA & \\
\hline 1982 & 69.89 & 1267 & 314.98 & 39.90797 & 0.571011 & NA & \\
\hline 1983 & 89.01 & 1267 & 412.84 & 52.30683 & 0.587651 & NA & \\
\hline 1984 & 82.20 & 1267 & 377.67 & 47.85079 & 0.582126 & NA & \\
\hline 1985 & 26.44 & 1267 & 316.83 & 40.14236 & 1.518244 & NA & \\
\hline 1986 & 20.72 & 1267 & 342.57 & 43.40362 & 2.094769 & NA & \\
\hline 1987 & 29.23 & 1267 & 449.59 & 56.96305 & 1.948787 & NA & \\
\hline 1988 & 33.72 & 1267 & 451.33 & 57.18351 & 1.695834 & NA & \\
\hline 1989 & 55.50 & 1267 & 367.6 & 46.57492 & 0.839188 & NA & \\
\hline 1990 & 110.93 & 1267 & 352.33 & 44.64021 & 0.402418 & NA & \\
\hline 1991 & 217.12 & 1267 & 366.72 & 46.46342 & 0.213999 & NA & \\
\hline 1992 & 194.43 & 1267 & 340.8 & 43.17936 & 0.222082 & NA & \\
\hline 1993 & 211.99 & 1267 & 371.89 & 47.11846 & 0.222267 & NA & \\
\hline 1994 & 516.20 & 1267 & 385.64 & 48.86059 & 0.094654 & NA & \\
\hline 1995 & 735.97 & 1267 & 387.56 & 49.10385 & 0.06672 & 5.8 & 0.007881 \\
\hline 1996 & 1050.29 & 1267 & 385.27 & 48.81371 & 0.046476 & 6.18 & 0.005884 \\
\hline 1997 & 1398.90 & 1267 & 340.78 & 43.17683 & 0.030865 & 6.07 & 0.004339 \\
\hline 1998 & 1449.60 & 1267 & 292.27 & 37.03061 & 0.025545 & 6.76 & 0.004663 \\
\hline 1999 & 1546.75 & 1267 & 261.35 & 33.11305 & 0.021408 & 7.41 & 0.004791 \\
\hline 2000 & 1655.74 & 1267 & 285.55 & 36.17919 & 0.021851 & 7.94 & 0.004795 \\
\hline 2001 & 2121.65 & 1608 & 268.35 & 43.15068 & 0.020338 & 8.55 & 0.00403 \\
\hline 2002 & 2864.07 & 1929 & 310.25 & 59.84723 & 0.020896 & 9.92 & 0.003464 \\
\hline 2003 & 4032.51 & 1929 & 356.53 & 68.77464 & 0.017055 & 11.00 & 0.002728 \\
\hline 2004 & 6099.32 & 1929 & 391.99 & 75.61487 & 0.012397 & 12.42 & 0.002036 \\
\hline 2005 & 8188.72 & 1929 & 430.66 & 83.07431 & 0.010145 & 12.58 & 0.001536 \\
\hline
\end{tabular}

Note: *: The data come from IMF database. \#: AFR is the actual Chinese Foreign Exchange Reserves; dimension of AFR is 100 million US Dollar; $\Omega$ : GR is the gold Reserves, dimension of GR is 10,000 ounces, and the value of GR is the statistic in the December of each year; $\Omega \Omega$ : GP is the gold price, we use the price of in the June of each year.dimension of GP is US dollar amount of each ounce; $\Omega \Omega \Omega$ : GV is the value of gold, dimension of GV is 100 million US Dollar. $\Psi$ : SDRs is the special drawing right, dimension of SDRs is 100 million US Dollar by our calculated; NA: NA is the data of not available. 